\title{
CRATER-LIKE HOLE AND COLOBOMA OF THE DISC ASSOCIATED WITH CHANGES AT THE MACULA
}

\author{
BY
}

\author{
DR. K. T. A. Halbertsma \\ DELFT, HOLLAND
}

THE presence of a hole in the disc constitutes one of the rarer congenital anomalies. Only some thirty cases have been published. von Hippel ${ }^{(1)}$ points out that the association of this anomaly with any other congenital defects (conus, coloboma, atrophy) is still rarer. James ${ }^{(2)}$ has published a case in which changes at the macula were present. His patient was a boy, aged six years, with a squint, so that no very accurate account of clinical symptoms attributable to the defect could be given.

Most writers on this subject do not consider that the mere presence of a hole at the disc gives rise to any symptoms. Any alterations in the visual field or in colour perception which may. be present are to be attributed to other defects. The case I am going to describe shows that the association of a hole in the disc with changes at the macula may give rise to pronounced alterations in the visual acuity, the perception of colour, and the visual fields. This condition must be very rare, since, as far as I know, no similar case has been published.

Mrs. S., aged 38 years, consulted me with regard to a change in the glasses which she had been wearing for the last five years. An ophthalmic surgeon whom she consulted in 1918 had told her that her left eye was defective. She gave a history of a blow on that eye and stated that, after this, she first noticed that the eye was defective. The patient's mother, who had died three years previously had had a defective left eye from birth. There was no other personal or family history of any anomaly.

On examination : V.R. $=8 / 10 \overline{\mathrm{c}}+1 \mathrm{D} . \mathrm{sph} .=10 / 10 .^{\circ}$ Visual field and colour perception are normal. V.L. fingers in the lower temporal quadrant, only the tips of the fingers being discerned in the upper temporal quadrant. The visual field for white (object $1 \mathrm{~cm}$. in diameter) shows, with the ordinary perimeter (Fig. 1) and with Bjerrum's screen (Fig. 2), an absolute central scotoma as well as some relative scotomata in the upper and lower temporal quadrants (Fig. 2). The sense of colour is obviously disturbed; green is called pale blue and red is called pink. Blue and yellow are recognized as such, but the visual field for these colours is far smaller than that for white. The red and green fields are so small that it is difficult to fix them with any precision.

Ophthalmoscopic examination of the left eye shows that the nasal half of the disc is normal; the vessels issue from the centre of the 
disc and run their usual course in the nasal half of the retina. The indirect view of the disc shows that the temporal half is occupied by a bluish-grey mass, close to the entrance of the bloodvessels, which resembles a cyst. Direct observation, however, shows (Plate) that the apparent cyst is really a crater-like hole with a diameter of about one-fifth that of the disc, clearly marked off from the surrounding white part of that structure. The bottom of the hole, which has a dark silver-grey colour is about 7-8D. below the level of the disc. The structure resembles the appearance

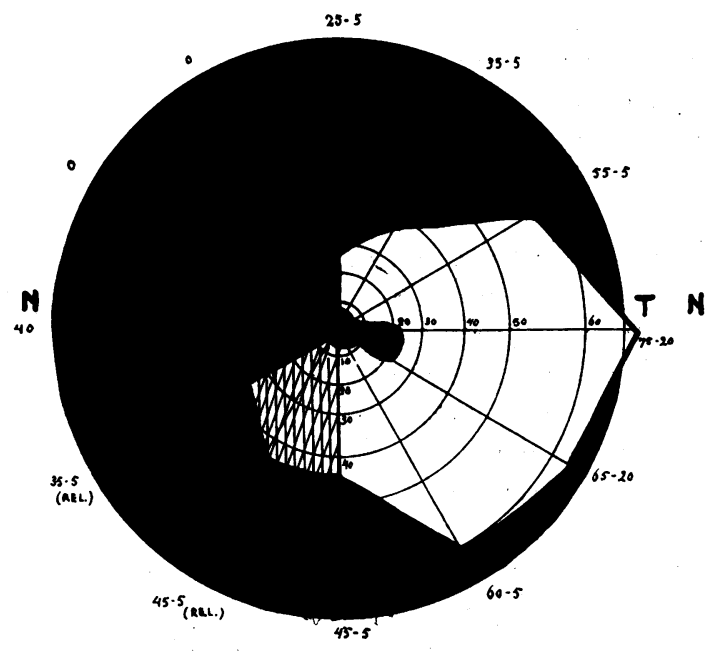

i [FIG. 1.

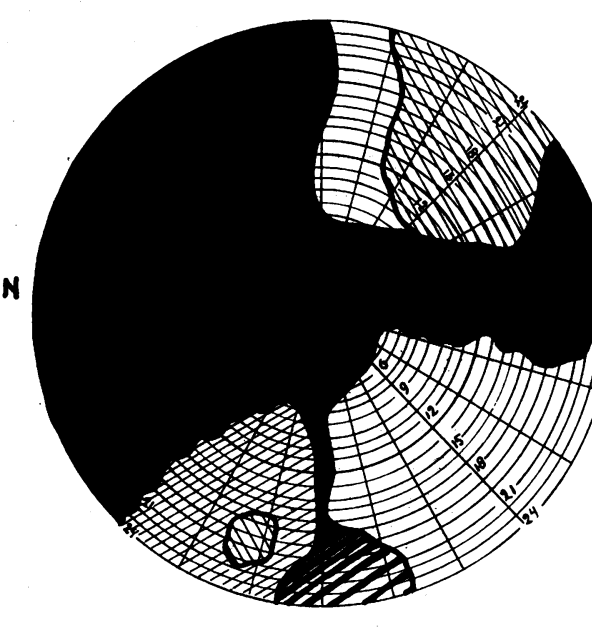

FIG. 2 .

of the lamina cribrosa as seen in a disc with deep excavation. The temporal half of the disc is on a slightly lower level than the nasal half. At the upper and lower sides of the hole some very thin irregularly-shaped arteries are visible as red lines issuing from the temporal arteries; these end somewhat abruptly at the disc margin. Within the hole itself no blood-vessels can be seen. The sclera is visible at the temporal edge of the disc and is surrounded by heaped up choroidal pigment. In the area between the disc and the macula there are numerous small yellow spots with many irregular dots of pigment scattered between them (see Plate). The macula is represented by an indefinite orange-coloured spot about the same diameter as the disc. The periphery of the fundus is normal.

The crater-like hole is the most important of the appearances described above. Such holes are usually single and situated in the horizontal meridian of the temporal half of the disc. Cases have been published in which there was more than one hole. Wiethe ${ }^{(3)}$ saw a case with one hole in each half of the disc. van 


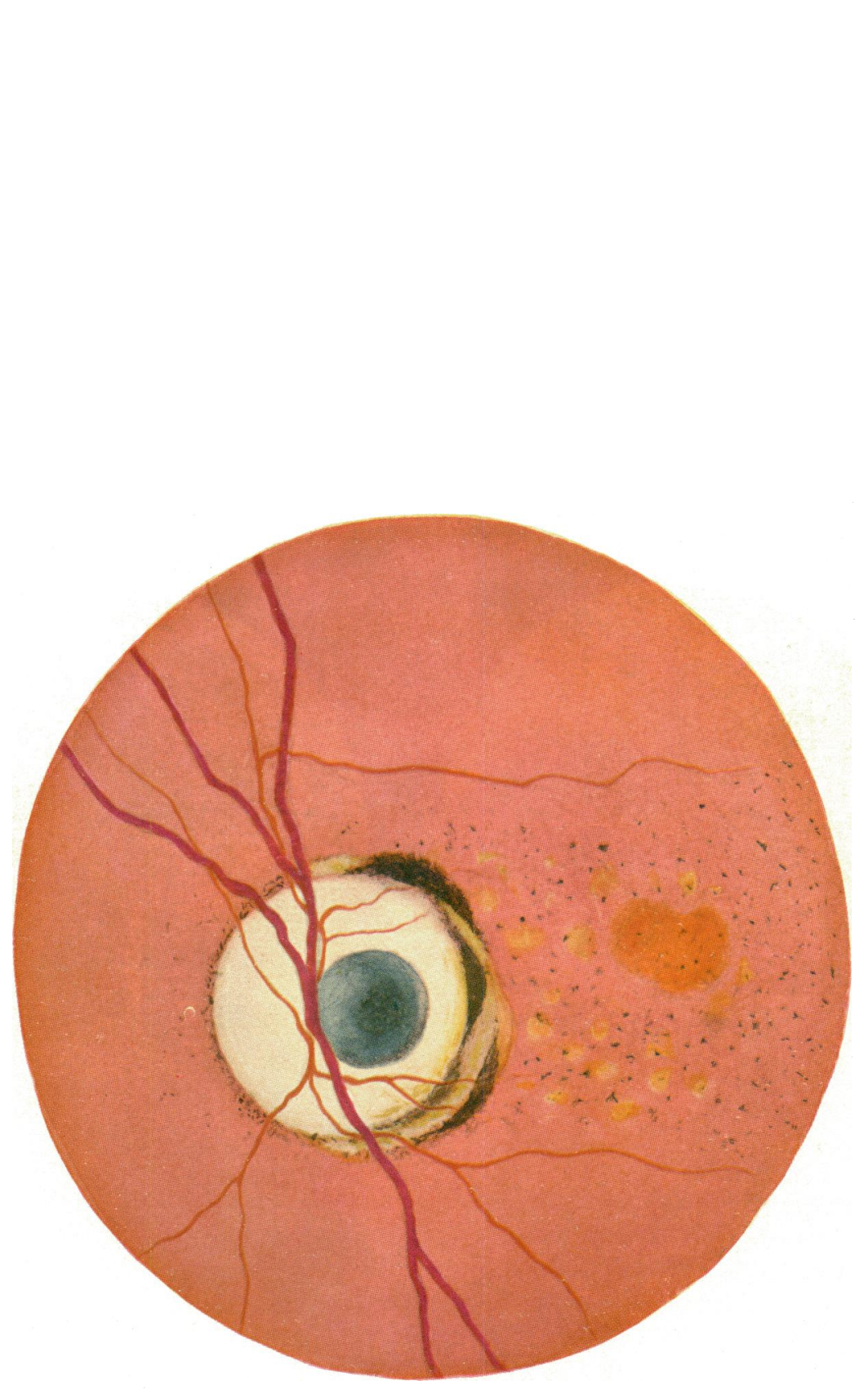


der Hoeve $\mathrm{e}^{(4)}$ described the case of a youth, aged 19 years, in whose right eye three holes were situated in a colobomatous disc. Two of these holes were in the upper and lower part of the nasal half of the disc and the third was in the upper part of the temporal half. The disc was represented by a large irregularly-shaped round white area of about nine times the diameter of a normal disc. The depth of the holes was about 5D. The blood-vessels issued irregularly, partly between the holes and partly at the outside of the disc. The visual acuity and the visual field for white were normal. The field for red, green, and blue showed a scotoma in the upper half. In the left eye there were colobomata of the iris, lens, choroid, and disc. The left eye had a squint, and in both eyes the cornea was smaller than normal. The colour of the holes was said to vary from dark grey to olive green, depending on the position of the ophthalmoscope, and their diameter was between one-eighth and one-third of a disc diameter.

The depth of the holes described shows considerable variation; thus Lichtenstein ${ }^{(5)}$ describes a depth of 24D., and Carsten ${ }^{(6)}$ one of $3 \mathrm{D}$. As von Hippel ${ }^{(1)}$ points out the emergence of a bundle of nerve or glia fibres may make the bottom of the hole invisible and so render any accurate estimation of its depth impossible.

Considerable differences have also been described in the relation of the vessels to the holes. Thus Wessely ${ }^{(7)}$ described two cases, in one of which a cilio-retinal artery, and in the other an opticociliary vein issued from the hole; and Prediger ${ }^{(8)}$ a case in which a cilio-retinal artery emerged between the two holes. In most cases, as in mine, no vessels are found in relation to the holes.

There is some difference of opinion as to the origin of the anomaly. The older authors (Wiethe, 1882 ; Stood, 1884 ; Remak, 1884 ; Szily, 1887; Reiss, 1908) on the whole considered the process to be a colobomatous one. Seefelder ${ }^{(9)}$ in his account of a patient with coloboma of iris, choroid, retina, and disc on one side and a pronounced hole in the disc on the other, says that the anomaly can only be explained on the assumption of a coloboma at the entrance of the optic nerve, due to the protrusion of the retina at the temporal side of the disc. The description and figures of his article seem to show, however, that a cystic protrusion of the retina was present at the outside of the disc of the same nature as that found in microphthalmic eyes. This case and that of Lauber ${ }^{(10)}$ are the only ones that have been examined anatomically. In the latter there was a cleft, prolonging the hole, which ran obliquely through the optic nerve towards the temporal pial sheath.

Wessely(n) thinks that these holes in the optic nerve form the entrance for blood-vessels which, either have not developed at all, or whose evolution has taken place too late; such vessels should originally issue from the posterior ciliary arteries. In 
lower mammals the retinal vessels in general issue from these latter, and the same may occur, as an atavistic symptom in man. Since the vessels described issue, as a rule, from the temporal side of the disc, this theory fits in with my observations to a certain extent, but is opposed by the fact that in many of the cases no vascularization at all has been found.

A remarkable case has been published by van Lint and van Duyse ${ }^{(11)}$ in which there were two symmetrically placed holes in both discs. In this case the vessels ran in a layer of retinal tissue which covered the holes in front. The visual acuity on the right side was $6 / 6$ and on the left $6 / 10$; both visual fields were of normal extent. The maculae and fundi were normal. The authors term the appearance that of cystic holes; a description supported by the glial or fibrous tissue that emerged from them and gave them the appearance of a cystic formation. They consider the process which gives rise to the formation of holes in the disc to be uniform with that which forms, according to Elschnig ${ }^{(12)}$ the origin of colobomata at the entrance of the optic nerve, viz., the protrusion of more or less developed folds of the retina in the disc itself or in its neighbourhood as a result of abnormal growth of retinal tissue at the margin of the secondary optic vesicle. According to the authors there is no essential difference between the holes in the lower half of the disc, the so-called typical ones, which may form the entrance to rather voluminous cysts and those which, as in my case, belong to the temporal half of the disc and whose infundibulum is rather short. The direction in which the growth of the retina takes place is of no essential interest; the dominating factor is that an abnormal growth of the retina takes place and forms folds which protrude in the disc or its immediate neighbourhood. The particular anomaly found, conus, scleral ectasia or hole in the disc, will depend on the way in which this process takes place. In accordance with this theory the authors speak of a colobomatous process which refers exclusively to anomalies of the disc.

Köhne ${ }^{(13)}$ published a case of a hole in the disc associated with changes in the visual field. He considered that the existence of an absolute central scotoma of oblong shape in the horizontal meridian indicated that the papillo-macular bundle had been interfered with. This symptom and the fact that there was an obvious difference in the prominence and colour of the centre and of the surrounding parts of the temporal half of the disc led him to think it very probable that a coloboma of the disc was also present. As a matter of fact, however, if the author's view was correct, the central scotoma should run from the central point to the blind spot, and not as shown in the figure, from the central point to the nasal side. It is, therefore, more probable that the scotoma observed was due to some change either at the macula 
or between the macula and the disc. The paper makes no mention of any such changes. The visual acuity was $6 / 18$, and there is no mention of any alteration in colour perception. At the end of his paper the author points out the desirability of recording any case of coloboma of the disc associated with a hole, as the nature of the visual field in such a case might throw light on the course and function of the nerve bundles running from the retina to the corresponding part of the disc.

As a rule, when a hole in the disc is present, no other changes inflammatory or otherwise have been observed in the retina. Carsten ${ }^{(14)}$ published a case with a paracentral scotoma corresponding to a retinal focus situated between the macula and the disc at about 1-2 disc diameters temporal from the disc. In the temporal half of the disc there was a hole about 3D. deep; this had given rise to no symptoms before the appearance of the retinal focus. The visual acuity then fell to $5 / 10$, but later recovered to the original 5/8. No relation between the retinal focus and the hole was apparent.

If a hole is found in any other part of the retina, similar to the holes on the disc, no changes in the visual field may be found. Scarlett ${ }^{(15)}$ observed a hole about two-thirds the diameter of the disc in the neighbourhood of the macula, about one and a quarter disc diameters from the disc. The visual acuity was $2 / 3$ and there was no alteration in the visual field. The aspect of the hole was very similar to that of a hole in the disc; the floor was white; and the hole was sharply limited from the surrounding retina. The origin of it was unknown. I have also seen a similar case in a girl, aged sixteen years. A few years before I saw her she had been treated elsewhere for disseminated choroiditis of the left eye and swelling of the disc of the right. On examination I found in the left eye a small round white hole above and to the temporal side of the disc at a distance about one-half disc diameter. The visual field showed no alteration and the visual acuity was $5 / 20$.

I believe that the changes in the fundus and functions of the eye in my case are best explained by the theory of van Lint and van Duyse ${ }^{(11)}$ to which I have already alluded. On the assumption, according to this theory, that at the place where the hole in the disc is situated, viz., the entrance of the papillo-macular bundle in the optic nerve, an abnormal growth of the retina has taken piace, the anomalies of the disc and of the region between the latter and the macula may be explained. According to this view the changes at the macula are of a secondary character. Since the normal development of the temporal half of the disc has been interfered with by an abnormal growth of retinal tissue this part 
of the disc has become colobomatous. In accordance with the theory this coloboma is an atypical one.

The fact that the mother of my patient may also have had a congenital anomaly of the eye lends some support to the theory of the colobomatous origin of the hole, as such defects are known to be frequently hereditary.

The disturbance of the functions of the eye can all be explained by the anomalies present in the fundus. The scotoma occupying the nasal half of the visual field and including the absolute central scotoma is apparently due to the coloboma of the temporal half of the disc and also to the changes observed between the disc and the macula. The disturbance in the colour sense is to be explained by the changes in the macula itself and in its immediate neighbourhood. The portions of the visual field which function correspond to the few remaining normal parts of the retina.

In the absence of any anatomical examination no other theory can well be suggested to explain all the facts observed. Possibly at some future date it may be possible to confirm the theory by direct microscopical observations.

\section{REFERENCES}

1. von Hippel. -Graefe-Saemisch Handb. f. Augenheilk., Vol. VIIB, 1923.

2. James.-Ophthal. Rev., p. 38, 1913.

3. Wiethe.-Arch.f. Augenheilk., p. 14, 1882.

4. van der Hoeve.-Arch.f. Augenheilk., p. 13, 1906.

5. Lichtenstein.-Berliner Ophthal. Gesell., 1907.

6. Carsten.-Zeitschr. f. Augenheilk., p. 79, 1924.

7. Wessely.-Arch.f. Augenheilk., p. 93, 1910.

8. Prediger.-Zeitschr. f. Augenheilk., p. 308, 1909.

9 Seefelder.-Arch. f. Ophthal., p. 129, 1915.

10. Lauber.-Zeitschr. f. Augenheilk., p. 494, 1909.

11. Van Lint and van Duvse.-Arch. d'Ophtal., p. 155, 1920.

12. Elschnig.-Arch.f. Ophthal., 1900.

13. Köhne.-Zeitschr.f. Augenheilk., p. 212, 1916.

14. Carsten.-Zeitschr. f. Augenheilk., p. 79, 1924

15. Scarlett.-Amer. Jl. of Ophthal., p. 467, 1925.

The following references, additional to those mentioned in the text, may be of interest to our readers.-(ED.).

Remak.-Centralbl.f. pract. Augenheilk., p. 225, 1884.

Stood.-Klin. Monatsbl.f. Augenheilk., Vol. XXII, p. 285, 1884.

Schnabel.-Wien. Med. Blatt., quoted by von Hippel in Graefe-Saemisch Handbuch, pt. i, chap. 9, p. 30, 1884.

Gunn.-Trans. Ophthal. Soc. U.K., Vol. VI, p. 74, 1886.

Szili.-Centralbl. f. pract. Augenheilk., pt. i, 1887.

Makrocki. -Centralbl. $f$. pract. Augenheilk., p. 264, 1888.

Peltesohn.-Centralbl. f. pract. Augenheilk., p. 339, 1888,

Bock.-Die angeborene Kolobome d. Augapfels., p. 71, 1893.

Dolganoff. - Arch. f. Augenheilk., Vol. XXVIII, p. 348, 1894.

Frost. - The Fundus Oculi, p. 83, 1896.

Dykmeister.-Arch.f. Augenheilk., Vol. XLVIII, p. 55, 1903

Thomson and Ballantyne.-Trans. Ophthal. Soc. U.K., Vol. XXIII, p. 277, 1903.

Levinsohn.-Berl. Ophthal. Gesell., reference in Zeitschr.f. Augenheilk. Vol. XV, p. 370, 1906. 
Reiss.-Zeitschr. f. Augenheilk., Vol. XIX, p. 505, 1908.

Mohr.-Zeitschr. f. Augenheilk., Vol. XX, p. 270, 1908.

Lauber.-Zeitschr.f. Augenheilk., Vol. XX, pp. 388, 583, 1908.

Herczogh.-Zeitschr. f. Augenheilk., Vol. XX, p. 270, 1908.

Fraenkel.-Ann. d'Ocul., Vol. CXLI, p. 101, 1909.

Stephenson. -The Ophthalmoscope, Vol. VII, p. 78, 1909.

Carr.-The Ophthalmoscope, Vol. VII, p. 742, 1909.

Coats. - . The pathology of colomboma at the nerve entrance." Roy. Lond. Ophthal. Hosp. Reps., Vol. XVII, p. 215.

Williams. -Ann. of Ophthal., Vol. XXII, p. 638, 1913.

Henderson, E. E-Proc. Roy. Soc. Med., Section of Ophthalmology, Vol. VII, p. 144

\title{
ON BITEMPORAL CONTRACTION OF THE VISUAL FIELD IN PREGNANCY
}

BY

\author{
DR. I. ABRAmowicz,
}

Senior Assistant in the University Eye Cinic of

PROF. SZYMANSKI, VILNO.

\section{I.-Introduction}

IT is generally known that pregnancy may be the cause of many diseases of the eye. Among the morbid changes, which occur in the course of regular pregnancy, may be cited: ecchymosis of the lids and of the conjunctiva, accommodative and muscular asthenopia, hyperaesthesia of the retina and night-blindness. Besides these slight and fleeting disturbances, there occur in pregnancy serious diseases, such as inflammation of the cornea and the uveal tract, diseases of the retina and optic nerve.

The above-mentioned diseases which depend in the main upon conditions associated with pregnancy, namely upon disorders of nutrition and disturbances of the internal secretion, are rare complications of pregnancy. According to Winckel their percentage is 1.4 per cent., according to Bastide only 1.3 per cent. This category contains only those diseases which are closely associated with pregnancy, usually recurring in subsequent pregnancies and disappearing after delivery or abortion.

Up to the present time no constant changes in the visual apparatus in connection with normal pregnancy, such as those found in the hypophysis, suprarenal and thyroid glands, were obtained.

Bosse (1900) tried to show that 75 per cent. of all women in a normal pregnancy show some disorders of the optic nerve, such as congestion and oedema of the disc, but the observations of Bosse were not confirmed by the investigations of other authors, such as Sandmann (1901), Polte (1905), and Majewski (1910). 